\title{
Personality, Emotional and Self-Assessed Intelligence and Right Wing Authoritarianism
}

\author{
Adrian Furnham \\ Department of Clinical, Heath and Educational Psychology, University College London, London, UK \\ Email: a.furnham@ucl.ac.uk
}

Received 7 November 2015; accepted 26 December 2015; published 29 December 2015

Copyright (C) 2015 by author and Scientific Research Publishing Inc.

This work is licensed under the Creative Commons Attribution International License (CC BY).

http://creativecommons.org/licenses/by/4.0/

c) (i) Open Access

\begin{abstract}
Two studies examined correlates of right-wing authoritarianism (RWA). In the first study ( $\mathrm{N}=260$ ), lower self-assessments of intelligence were associated with higher RWA scores. In the second study $(\mathrm{N}=328)$, personality traits and emotional intelligence but not self-assessed intelligence were related to RWA beliefs. Higher RWA scorers tended to be Closed-to-Experience, Conscientious, and Neurotics with higher trait emotional intelligence. Together these accounted for $20 \%$ of the variance.
\end{abstract}

Keywords

Right-Wing Authoritarianism, Personality, Intelligence

\section{Introduction}

Altemeyer's (Altemeyer, 1981, 1988, 1996, 1998) theory of right-wing authoritarianism (RWA) revived interest on individual difference determinants of prejudice (Duriez \& Soenens, 2009; Mavor, Macloed, Boal, \& Louis, 2009). This was spurred on by the development of long and short versions of a psychometrically validated questionnaire (Rattazzi, Bobbio, \& Canova, 2007).

A great deal of the literature in this area has been dominated by those with a social psychological perspective who see prejudice originating from a social dominance orientation, as well as group formation and identification (Turner, 1991). The social psychologists have suggested that prejudice originates from the process of establishing personal identity and differentiating oneself and one's group from others. They see this not linked to personality but social forces. Other researchers have investigated the genetic and environmental influences associated with RWA. McCourt, Bouchard, Lykken, Telligen, \& Keyes (1999) found that genetic factors accounted for 50\% 
and unshared environment for 35\% of the phenotypic variance. They found RWA negatively correlated with general cognitive ability although it did not underline the twin correlates on authoritarianism. This finding was unexpected.

A few studies have looked at personality correlates of RWA (Heaven \& St. Quintin, 2003), each using different measures of the Big Five. Van Hiel, Mervielde, \& De Fruyt (2004) looked at the relationship between maladaptive personality traits and the RWA. Using the Dimensional Assessment of Personality Pathology Basic Questionnaire and the Big Five NEO-FFI, they found that "Openness" was the most powerful correlate followed by "Conscientiousness". Two maladaptive traits "Disagreeableness" and "Compulsivity" were also significantly positively associated with the RWA score. Recently, Akrami \& Ekehammar (2006) tested 332 Swedish students on the RWA and the Big Five and found "Openness", the only significant predictor of RWA at the factor/domain level. However, there was also evidence that "Agreeableness" was related to RWA. Authoritarians tended to be low on "Openness" and "Agreeableness" but high on "Conscientiousness". Because of the variance explained by five facets (namely 40\%), Akrami and Ekehammar concluded that social psychologist had been wrong to reject personality trait explanations for prejudice.

This paper examines, in two separate studies, three correlates of RWA scores in two student samples. The first study investigates the relationship between trait emotional intelligence and RWA beliefs. Authoritarianism beliefs are essentially non-empathic and misanthropic, while emotional intelligence is associated with agreeableness, tender-mindedness and empathy motional intelligence concerns emotional sensitivity and management. Hence, it was predicted that there would be a negative association between RWA and trait emotional intelligence $(\mathrm{H} 1)$.

These studies will also examine the relationship between self-assessed intelligence (SAI) and RWA. Whilst the literature suggests a modest negative correlation between actual psychometric intelligence and RWA, it is not clear whether the same will hold for SAI. The literature of SAI suggests first that it correlates between $r$ $=.30$ and $r=.50$ with psychometric intelligence; second that males tend to express hubris and females humility; third that SAI is related modestly to personality with Stable, Open, Disagreeable people giving higher scores (Furnham, 2001, 2008). Given the personality characteristics of RWA scores, it was predicted that there would be modest significant negative correlations between SAI and RWA scores (H2).

Finally, the second study will examine personality correlates of RWA. Based on previous research (Akrami \& Ekehammar, 2006; Heaven \& St. Quintin, 2003; Van Hiel, Mervielde, \& De Fruyt, 2004), it is predicted that four of the Big Five will show significant correlations in the following order of size: Openness (negative), Conscientiousness (positive), Agreeableness (negative), Neuroticism (positive) (H3). Another aim of this study is to investigate how much variance the three independent variables (Trait EI, SEI, Big Five) account for in totaling RWA scores.

\section{Study 1}

This study aimed to test the relationship between RWA, self-assessed intelligence and trait emotional intelligence.

\subsection{Method}

\subsubsection{Sample}

Participants were 260 (175 female, 85 male) British and American students. Their ages ranged from 18 to 50 years $(M=22.21, S D=5.89)$ and the majority of the sample was composed of students $(65 \%)$. They were drawn from two universities in London which had a number of visiting students. None were students of psychology.

\subsubsection{Measures}

1) Right Wing Authoritarianism (RWA; Altemeyer, 1988). The RWA is a 30-iteminstrucment, using a 9 point Likert scale. The range was from $-4=$ very strongly disagree to $+4=$ very strongly agree designed to assess psychological authoritarianism. Higher scores indicate lower authoritarianism levels. In the present study the internal consistency was $\alpha=.90$.

2) Self-Assessed Intelligence (SAI). SAI was assessed through an 11-item questionnaire, which required participants to rate their abilities ((e.g., spatial, mathematical, social, verbal, etc.)—on a normal distribution/standardized bell curve (Chamorro-Premuzic \& Furnham, 2006). In the present study the internal reliability was $\alpha$ 
$=.89$.

3) Emotional Intelligence (EQ; Schutte, Malouff, Hall, Haggerty, Cooper, Golden, \& Dornheim, 1998). EQ is a 33-item, 7 point Likert questionnaire, based on the emotional intelligence model of Salovey \& Mayer (1990), $\alpha=.88$.

\subsection{Results}

Descriptive statistics, sex effects and correlations. Descriptive statistics were computed for all measures. Next, independent $t$ tests were performed to test sex effects on RWA, SAI and EQ. As seen in Table 1, there were no sex differences in any of the assessed variables.

Bivariate correlations were computed and revealed significant, albeit small, associations between RWA and SAI $(r=-.21, p<.01)$, and between SAI and EQ $(r=.26, p<.01)$. Conversely, the correlation between RWA and EQ was not significant $(r=-.13)$.

RWA Predictors. A series of multiple hierarchical regressions was performed in order to investigate whether SAI (Block 1) and EQ (Block 2) significantly predicted RWA scores. Results revealed that SAI, but not EQ, was a significant predictor (see Table 2). However, the explained variance accounted for was only $4 \%$.

Those with lower self-assessed intelligence were higher on RWA, which is in line with the hypotheses. However there was no relationship between EQ and RWA. We did not have data on the participants' actual IQ scores but the self-estimated IQ scores can act as a proxy (Furnham, 2001). Thus these results confirm many other studies which have shown that liberal as opposed to authoritarian attitudes are related to general intelligence.

\section{Study 2}

Study 2 attempted to replicate Study 1 results, using different measures. Therefore, a different version of the SAI as well as another EQ measure was used. Moreover, it aimed to investigate incremental validity of SAI and EQ above the Big Five personality traits, described above.

\subsection{Method}

\subsubsection{Sample}

In all, 328 (157 males, 171 females) university students from England ( $N=185 ; 117$ males, 68 females $)$ and the United States $(N=143,40$ males, 103 females) participated on the study. Age ranged from 17 to 47 years $(M=$ $19.54, S D=3.78$ ). There was no difference between the two national groups on any of the variables.

Table 1. Descriptive statistics and sex effects on RWA, SAI \& EQ.

\begin{tabular}{ccccc} 
& \multicolumn{3}{c}{ M (SD) } & \multirow{2}{*}{ Males } \\
\cline { 2 - 4 } & Total sample & Females & $93.36(26.94)$ & 1.70 \\
RWA & $97.28(23.84)$ & $99.17(22.35)$ & $111.22(12.84)$ & 1.69 \\
EQ & $109.45(11.26)$ & $108.61(10.36)$ & $168.22(18.01)$ & 0.84 \\
\hline
\end{tabular}

Note: RWA = Right-wing authoritarianism. SAI = Self-assessed intelligence. EQ = Emotional intelligence questionnaire.

Table 2. Multiple hierarchical regression of RWA onto SAI and EQ.

\begin{tabular}{|c|c|c|c|c|c|c|c|}
\hline & \multicolumn{7}{|c|}{ RWA } \\
\hline & $\mathrm{B}(\mathrm{SD})$ & $\beta$ & $\mathrm{t}$ & $F(d f)$ & $\mathrm{R}$ & $\Delta \mathrm{R}^{2}$ & $p$ \\
\hline Model 1 & & & & $\mathrm{~F}(1,194)=10.24^{* *}$ & .22 & .04 & .05 \\
\hline SAI & $-.01(.005)$ & -.22 & $3.20^{* *}$ & & & & \\
\hline Model 2 & & & & $\mathrm{~F}(2,193)=5.78^{* *}$ & .23 & .04 & .006 \\
\hline SAI & $-.01(.005)$ & -.20 & $2.78^{* *}$ & & & & \\
\hline EQ & $-.11(.09)$ & -.08 & 1.14 & & & & \\
\hline
\end{tabular}

Note: ${ }^{*} p<.05,{ }^{* *} p<.01$. RWA = Right-wing authoritarianism. SAI = Self-assessed intelligence. EQ = Emotional intelligence questionnaire. 


\subsubsection{Measures}

1) RWA. As in Study 1, in the present study internal reliability was $\alpha=.91$.

2) Self-Assessed Intelligence (SAI). Participants were asked to estimate eight abilities (i.e., cognitive/reasoning, verbal, numerical, emotional, general knowledge, social, creative, and spatial). A normal distribution scale ranging from -3 (mild retardation) to +3 (gifted) was provided as reference as well as a brief description for each ability domain. The arithmetic mean was computed for each participant. Cronbach's alpha was $\alpha=.77$.

3) Trait Emotional Intelligence (TEIQue; Petrides \& Furnham, 2000). This is a 30-item questionnaire designed to measure global trait emotional intelligence (trait EI). It is based on the long form of the TEIQue and comprises two items from each of the 15 subscales of the TEIQue (Petrides \& Furnham, 2000). In the present study $\alpha=.84$.

4) Neuroticism-Extraversion-Openness Five Factor Inventory (NEO-FFI) (Costa \& McCrae, 1992). This is a 60-item scale designed to assess the five major personality traits. Participants are asked to respond to each statement on a 5-point Likert scale, ranging from 0 (strongly disagree) to 4 (strongly agree) (see ChamorroPremuzic, 2007; Costa \& McCrae, 1992 for evidence of reliability).

\subsection{Results}

Descriptive statistics \& sex effects. Table 3 shows descriptive statistics and sex effects (independent $t$ tests) on all target variables. There were no sex differences in RWA, SAI scores and Neuroticism; however women scored significantly higher on Extraversion, Openness to Experience, Conscientiousness and TEIQue, whilst men revealed higher scores on Agreeableness.

RWA Predictors. Bivariate correlations were computed in order to examine the relationship between RWA, SAI, TEIQue and Big Five personality traits. Results revealed small, but significant associations between RWA, TEIQue and Extraversion. Moreover, medium significant associations were observed between RWA, Openness and Conscientiousness (see Table 4).

Table 3. Descriptive statistics and sex effects on RWA, SAI \& EQ.

\begin{tabular}{|c|c|c|c|c|}
\hline & \multicolumn{3}{|c|}{$\mathrm{M}(\mathrm{SD})$} & \multirow{2}{*}{$t$} \\
\hline & Total sample & Females & Males & \\
\hline RWA & 134.15 (34.57) & 133.17 (37.28) & $135.22(31.46)$ & 0.53 \\
\hline SAI & 39.53 (4.89) & $40.01(5.15)$ & $39.01(4.56)$ & -1.78 \\
\hline TEIQue & $140.00(22.26)$ & $145.60(21.10)$ & 133.79 (21.93) & $4.93^{* *}$ \\
\hline Neuroticism & 35.27 (6.57) & 35.85 (7.08) & 34.64 (5.94) & 1.65 \\
\hline Extraversion & $41.56(5.80)$ & $42.18(6.24)$ & $40.88(5.21)$ & $2.30^{*}$ \\
\hline Openness & $37.93(5.51)$ & 38.88 (5.74) & $36.89(5.07)$ & $3.30^{* *}$ \\
\hline Agreeableness & 31.58 (5.58) & 30.12 (5.87) & $33.17(4.77)$ & $5.12^{* *}$ \\
\hline Conscientiousness & 42.59 (5.26) & 43.64 (5.85) & $41.45(4.27)$ & $3.83^{* *}$ \\
\hline
\end{tabular}

Note: ${ }^{*} p<.05,{ }^{* *} p<.01$. RWA = Right-wing authoritarianism. SAI = Self-assessed intelligence. EQ = Emotional intelligence questionnaire.

Table 4. Bivariate correlations between RWA, SAI, TEIQue \& Big Five.

\begin{tabular}{lccccccc}
\hline & 2 & 3 & 4 & 5 & 6 & 7 & 8 \\
\hline${ }^{1}$ RWATotal & .01 & $.11^{*}$ & .01 & $.12^{*}$ & $-.34^{* *}$ & -.04 & $.30^{* *}$ \\
${ }^{2}$ SAI & & $.27^{* *}$ & $-.15^{* *}$ & $.13^{*}$ & $.14^{*}$ & -.03 & $.20^{* *}$ \\
${ }^{3}$ TEIQue & & $-.33^{* *}$ & $.44^{* *}$ & $.20^{* *}$ & $-.39^{* *}$ & $.40^{* *}$ \\
${ }^{4}$ Neuroticism & & & $-.28^{* *}$ & $.16^{* *}$ & $.21^{* *}$ & $-.21^{* *}$ \\
${ }^{5}$ Extraversion & & & & -.04 & $-.22^{* *}$ & $.20^{* *}$ \\
${ }^{6}$ Openness & & & & & & $-.17^{*}$ & $-.11^{*}$ \\
${ }^{7}$ Agreeableness & & & & & & & $-.29^{* *}$ \\
${ }^{8}$ Conscientiousness & & & & & & & \\
\hline
\end{tabular}

Note: ${ }^{*} p<.05,{ }^{* *} p<.01$. RWA = Right-wing authoritarianism. SAI = Self-assessed intelligence. $\mathrm{EQ}=$ Emotional intelligence questionnaire. 


\section{Discussion}

The results of these two studies showed three things. First, self-assessed/estimated intelligence is tangentially related to RWA. The measures used in the two studies were not identical and while there was a modest significant result in the first study, this was not replicated in the second. Whilst various authors (e.g. McCourt et al., 1999) have suggested that authoritarianism is associated with lower IQ and educational attainment, it is has been established that the correlation between estimated and test-derived IQ scores is modest.

The results from the EQ measure are more surprising. The first study found no relationship between RWA and EQ; however, in the second study with a larger $\mathrm{N}$ and a psychometrically more robust measure there was a positive relationship both in the correlation and the regression. While the size of the correlation was very modest $(r=.11)$ and the amount of incremental variance accounted for small (1\%), it remained uncertain as to how to interpret this finding. The effect size suggests that essentially these two concepts are unrelated.

The results from the second study do support previous studies, showing that RWA beliefs are associated with low "Openness" and high "Conscientiousness". This replicates the study by Van Hiel et al. (2004) from Belgium and to some extent that of Akrami \& Ekehammar (2006) from Sweden. However, there are two differences from previous studies, which are clear in the final regression (Table 5) which shows that RWA beliefs are significantly related to "Neuroticism", but not "Agreeableness". Neither the correlation nor the regression analysis shows "Agreeableness" related to RWA beliefs. However, few previous studies have shown "Neuroticism" linked to RWA beliefs, though this does fit with Van Hiel et al.'s (Van Hiel et al., 2004) conception of the RWA beliefs being associated with maladaptive personality traits.

The second study shows that Right-Wing Authoritarians tend to be Closed to Experience, Conscientious, Neurotics. They may be described as lacking in imagination and curiosity, while being moody, anxious and irritable while yet efficient and industrious.

Table 5. Multiple hierarchical regression of RWA onto Big Five, SAI and TEIQue.

\begin{tabular}{|c|c|c|c|c|c|c|c|}
\hline & \multicolumn{7}{|c|}{ RWA } \\
\hline & $\mathrm{B}(\mathrm{SD})$ & $\beta$ & $\mathrm{t}$ & $\mathrm{F}(\mathrm{df})$ & $\mathrm{R}$ & $\Delta \mathrm{R} 2$ & $\mathrm{p}$ \\
\hline Model 1 & & & & $F(5,286)=15.44^{* *}$ & .46 & .19 & .21 \\
\hline $\mathrm{N}$ & $.02(.01)$ & .14 & $2.55^{*}$ & & & & \\
\hline $\mathrm{E}$ & $.01(.01)$ & .09 & 1.69 & & & & \\
\hline $\mathrm{O}$ & $-.07(.01)$ & -.33 & $6.12^{* *}$ & & & & \\
\hline A & $-.007(.01)$ & -.03 & .62 & & & & \\
\hline $\mathrm{C}$ & $.05(.01)$ & .27 & $4.90^{* *}$ & & & & \\
\hline Model 2 & & & & $F(6,285)=12.84^{* *}$ & .46 & .19 & .001 \\
\hline $\mathrm{N}$ & $.02(.01)$ & .14 & $2.56^{*}$ & & & & \\
\hline $\mathrm{E}$ & $.01(.01)$ & .09 & 1.65 & & & & \\
\hline $\mathrm{O}$ & $.07(.01)$ & -.33 & $6.05^{* *}$ & & & & \\
\hline A & $.008(.01)$ & -.03 & .65 & & & & \\
\hline $\mathrm{C}$ & $.05(.01)$ & .27 & $4.71^{* * *}$ & & & & \\
\hline SAI & $.03(.10)$ & .01 & .30 & & & & \\
\hline Model 3 & & & & $F(7,284)=11.86^{* *}$ & .47 & .20 & .01 \\
\hline $\mathrm{N}$ & $.03(.01)$ & .17 & $3.01^{* *}$ & & & & \\
\hline $\mathrm{E}$ & $.01(.01)$ & .04 & .80 & & & & \\
\hline $\mathrm{O}$ & $.07(.01)$ & -.37 & $6.47^{* * *}$ & & & & \\
\hline A & $-.002(.01)$ & -.01 & .18 & & & & \\
\hline $\mathrm{C}$ & $.05(.01)$ & .23 & $3.90^{* *}$ & & & & \\
\hline SAI & $.001(.10)$ & .01 & .01 & & & & \\
\hline TEIQue & $.008(.004)$ & .15 & $2.21^{*}$ & & & & \\
\hline
\end{tabular}


Studies, such as this, suffer from problems of method invariance and the possibility of item overlap, as well as using student participants. Nevertheless, it confirms the findings of Akrami \& Ekehammar (2006) that around a fifth to a quarter of the variance in RWA can be accounted for by personality traits. They argued that whilst the early work in the 1950's on prejudice indeed focused on personality (The Authoritarian Personality; Adorno, Frenkel-Bruswik, Levinson, \& Sanford, 1950), most of the research and theorising on prejudice and discrimination had been dominated by social psychologists who had vigorously rejected trait explanations in favour of self-categorization and social identity theory. They believe that these two approaches can be integrated to give a much fuller description and explanation for the development and application of RWA beliefs.

\section{References}

Adorno, T., Frenkel-Brunswik, E., Levinson, D., \& Sanford, R. (1950). The Authoritarian Personality. New York: Norton.

Akrami, N., \& Ekehammar, B. (2006). Right-Wing Authoritarianism and Social Dominance Orientation. Journal of Individual Differences, 27, 117-126. http://dx.doi.org/10.1027/1614-0001.27.3.117

Altemeyer, B. (1981). Right-Wing Authoritarianism. Winnipeg: University of Manitoba Press.

Altemeyer, B. (1988). Enemies of Freedom: Understanding Right-Wing Authoritarianism. San Franciso: Jossey-Bass.

Altemeyer, B. (1996). The Authoritarian Specter (pp. 374). Cambridge, MA: Harvard University Press.

Altemeyer, B. (1998). The Other “Authoritarian” Personality. Advances in Experimental Social Psychology, 30, 47-91. http://dx.doi.org/10.1027/1614-0001.27.3.117

Chamorro-Premuzic, T. (2007). Personality and Individual Differences. Oxford: Blackwell.

Chamorro-Premuzic, T., \& Furnham, A. (2006). Self-Assessed Intelligence and Academic Performance. Educational Psychology, 26, 769-779. http://dx.doi.org/10.1027/1614-0001.27.3.117

Costa Jr., P. T., \& McCrae, R. R. (1992). Revised NEO Personality Inventory (NEO-PI-R) and NEO Five Factor Inventory (NEO-FFI): Professional manual. Odessa, FL: Psychological Assessment Resources.

Duriez, B., \& Soeners, B. (2009). The Intergenerational Transmission of Racism. Journal of Research in Personality, 43, 906-909. http://dx.doi.org/10.1016/j.jrp.2009.05.014

Furnham, A. (2001). Self-Estimates of Intelligence. Personality and Individual Differences, 31, 1381-1405. http://dx.doi.org/10.1016/S0191-8869(00)00232-4

Furnham, A. (2008). Personality and Intelligence at Work. London: Routledge. http://dx.doi.org/10.4324/9780203938911

Heaven, P., \& Quintin, D. (2003). Personality Factors Predict Racial Prejudice. Personality and Individual Differences, 34, 625-634. http://dx.doi.org/10.1016/S0191-8869(02)00046-6

Mavor, K., Macleod, C., Boal, M., \& Louis, W. (2009) Right-Wing Authoritarianism, Fundamentalism and Prejudice Revisited. Personality and Individual Differences, 46, 592-597. http://dx.doi.org/10.1016/j.paid.2008.12.016

McCourt, K., Bouchard, T., Lykken, D., Tellegen, A., \& Keyes, M. (1999). Authoritarianism Revisited: Genetic and Environmental Influences Examined in Twins Reared Apart and Together. Personality and Individual Difference, 27, 9851014. http://dx.doi.org/10.1016/S0191-8869(99)00048-3

Petrides, K. V., \& Furnham, A. (2000). On the Dimensional Structure of Emotional Intelligence. Personality and Individual Differences, 29, 313-320. http://dx.doi.org/10.1016/S0191-8869(99)00195-6

Rattazzi, A., Bobbio, A., \& Canova, L. (2007). A Short Version of the Right-Wing Authoritarianism (RWA) Scale. Personality and Individual Differences, 43, 1223-1234. http://dx.doi.org/10.1016/j.paid.2007.03.013

Salovey, P., \& Mayer, J. D. (1990). Emotional Intelligence. Imagination, Cognition, and Personality, 9, 185-211. http://dx.doi.org/10.2190/DUGG-P24E-52WK-6CDG

Schutte, N. S, Malouff, L. M., Hall, L. E., Haggerty, D. J., Cooper, J. T., Golden, C. J., \&. Dornheim, J. (1998). Development and Validation of a Measure of Emotional Intelligence. Personality and Individual Differences, 25, 167-177. http://dx.doi.org/10.1016/S0191-8869(98)00001-4

Turner, J. (1991). Social Influence. Buckingham: Open University Press.

Van Hiel, A., Mervielde, I., \& De Fruyt, F. (2004). The Relationship between Maladaptive Personality and Right Wing Ideology. Personality and Individual Differences, 36, 405-417. http://dx.doi.org/10.1016/S0191-8869(03)00105-3 